\title{
Implementasi Nilai-Nilai Aqidah Akhlaq Dalam Meningkatkan Kepedulian Sosial
}

\author{
Maftuchaturrohmah ${ }^{1}$ Layli Masruroh ${ }^{2}$ \\ ${ }^{1}$ Pendidikan Agama Islam, Fakultas Pendidikan Agama Islam, Universitas Hasyim Asy'ari
}

Article Info

Article history:

Received Agustus 17, 2019

Accepted September 3, 2019

\section{Keywords:}

Aqidah Akhlaq Values

Social Concern

Islamic Education

\begin{abstract}
One of the subjects taught at school is Aqidah Akhaq. This learning is done to instill good aqidah and morality to students. But with just learning it seems lacking without any implementation of the learning. The title of this research is "implementation of the values of aqidah akhlaq in increasing social awareness of case studies in class X MA al Qur'an La Raiba Hanifida" with a focus of research on the values of aqidah akhlaq students of MA al Quran La Raiba Hanifida and how it is implemented towards social care. The purpose of this research is to find out the implementation of Aqeedah Ahlaq towards social care case studies in class X MA al Quran La Raiba Hanifida. This research uses descriptive qualitative. Ways to collect data by interview, observation and documentation. While data collection techniques by reducing data and verifying data. Based on the results of research conducted that the values or attitudes of students of class X MA al Qur'an La Raiba Hanifida differ from one another. This is influenced by different family backgrounds, schools and environments. To equalize and increase the social awareness of students at the MA al Qur'an, La Raiba Hanifida collaborates with pesantren to hold several activities that are expected to be able to increase the social awareness of students. Among these activities include: teaching asthma pilgrims, teaching flash pupils and TPQ, training, engaging in all events, social and social services.
\end{abstract}

This is an open access article under the CC BY-SA license.

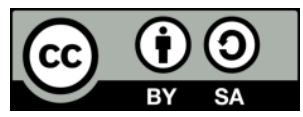

\section{Corresponding Author:}

Maftuchaturrohmah

Prodi Pendidikan Agama Islam, Fakultas Agama Islam, Universitas Hasyim Asy’ari (UNHASY)

Email: tukijah1@gmail.com

\section{PENDAHULUAN}

Anak merupakan anugerah yang sangat berharga yang diberikan oleh Allah kepada hambanya. Tidak semua orang mendapapatkan anugerah yang sebesar ini. Banyak hambanya yang menginginkan akan tetapi Allah belum memberikannya. Karena itu bagi hambanya yang sudah mendapatkan titipan dari tuhan ini hendaknya mengarahkan anaknya sebaik mungkin dalam hal akhlak dan segala sesuatunya. Masa depan bangsa dan dunia juga akan menjadi cerminan dari pribadi anak. Jika akhlak anak tersebut baik serta mempunyai aqidah yang kuat maka tidak menutup kemungkinan masa depan bangsa dan dunia cerah. Dan sebaliknya jika didikan anak dari kecil sudah tidak mencerminkan akhlak yang baik dan tidak mempunyai aqidah yang kuat maka masa depan bangsa dan dunia akan menjadi gelap. Dalam rangka mendidik anak salah satu yang harus dibenahi dan didalami adalah tentang aqidah akhlaq. Dengan mepunyai aqidah akhlaq yang dan kuat maka walaupun ada goncangan dan hiasan dunia yang berat maka ia tidak akan goyah (Al Atsari Abduloh, 2006:34)

Memiliki aqidah akhlaq yang baik sangat penting. Karena Allah mengutus Nabi Muhammad sebagai Nabi akhir zaman adalah untuk menyempurnakan akhlaq. Sebagaimana sabda Nabi:

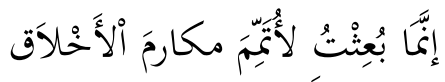

“Sesungguhnya aku hanya diutus untuk menyempurnakan akhlak yang mulia (Anas Miftah, 2012:15) 
Sabda Nabi tersebut juga dikuatkan dengan firman Allah yang berbunyi:

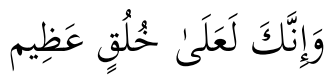

Yang artinya : Dan sesungguhnya ia berbudi pekeri yang agung

Dari keterangan di atas serta dikuatkan dalil di atas sangat menegaskan bahwa penting sekali mempunyai akhlak yang baik. Apalagi zaman sekarang diiringi dengan melejitnya tekhnologi yang terus berkembang dengan kemajuan zaman mau tidak mau manusia juga harus mengikutinya agar tidak ketinggalan zaman. Akan tetapi dari melejitnya tekhologi tersebut disini juga sangat diperlukan pengawasan yang khusus kepada anak karena tekhnologi bagaikan mempunyai dua sisi. Yang satu negative dan satunya positive. Dengan adanya tekhnologi jika tidak diimbangi untuk membentengi diri dari godaangodaan yang ada didalamnya maka anak akan terjerumus kepada hal yang tidak baik (Yuliandi Kusuma dan Ardy Artanto 2011:18)

Menurut Zulkarnain akhlak adalah bentuk dari pengamalan dari perbuatan yang baik dan sebagai puncak yang tinggi dari keimanan dan keislaman seorang hamba. (Zuhraini.1995:51) Sasaran utama diadakannya pendidikan aqidah akhlak di sekolah antara lain ingin anak didik bisa meningkatkan keimanan serta bisa mengamalkan nilai-nilai ajaran islam didalam kehidupan agar menjadi pribadi yang berguna bagi keluarga, Nusa dan Bangsa (Abdul Majid dan Dian Andyani, 2008:135). Manusia secara hakiki adalah makhluk sosial yang berarti bahwa manusia tidak bisa berdiri sendiri. Namun pasti memerlukan bantuan orang lain dalam kehidupannya (Gerungan,2004:26)

Melalui iplementasi nilai-nilai aqidah akhlaq di kelas X MA al Qur'an La Raiba Hanifida bukan satusatunya cara untuk meningkatkan kepedulian sosial akan tetapi ditunjang juga dengan kegiatan yang lain. MA al Qur'an La Raiba Hanifida berlokasikan di Bandung Kencur Diwek, Jombang. Sekolah merupakan sekolah swasta yang berdiri dalam naungan yayasan La Raiba Hanifida yang berlokasikan di Depan Pasar Bandung Diwek Jombang Jawa Timur. Dari pemaparan di atas peneliti ingin meneliti lebih dalam tentang sekolah tersebut yang berkaitan dengan implementasi nilai-nulai aqidah akhlaq dalam meningkatkan kepedulian sosial di kelas X MA al Qur'an La Raiba Hanifida dan digunakan sebagai judul penulisan skripsi dengan focus penelitiannya sebagai berikut: (1) Bagaimana nilai-nilai aqidah akhlaq kelas X MA al Qur'an La Raiba Hanifida? (2) Bagaimana implementasi nilai-nilai aqidah akhlaq dalam meningkatkan kepedulian sosial kelas X MA al Qur'an La Raiba Hanifida? Berangkat dari konteks dan focus penelitian diatas maka peneliti menetapkan tujuan dari penelitian ini sebagai berikut: (1) Untuk mengetahui nilai-nilai aqidah akhlaq kelas X MA al Qur'an La Raiba Hanifida. (2) Untuk menetahui implementasi nilai-nilai aqidah akhlaq dalam meningkatkan kepedulian sosial kelas X MA al Qur'an La Raiba Hanifida.

K. Bertens didalam bukunya "etika" mengatakan bahwa nilai itu adalah sesuatu yang memunyai konotasi positif sesuatu yang baik, yang berharga, dan memiliki sesuatu arti, dan nilai itu adalah sesuatu yang mempunyai arti yang harus kita perjuangkan. Seorang filsuf Jerman- Amerika, Hans Jonas melukiskan bahwa nilai itu the addressee of a yes " sesuatu yang ditujukan dengan " ya " kita " jadi nilai adalah sesuatu yang kita iyakan.(Antonius Antoshoki, 2005:114). Sedangkan menurut Ali Saifulloh mngatakan bahwa nilai adalah: sesuatu yang dianggap berharga dan dijadikan sebagai kriteria untuk menentukan benar atau tidaknya tingkah laku manusia yang menjunjung nilai tersebut. Pengenalan dan penentuan pilihan tentang nilai-nilai yang mana yang akan digunakan oleh manusia. (Ali Saifulloh,1982:34). Contoh dari nilai yang baik antara lain adalah: (1) Menyebarkan ilmu(2) Gotong royong(3)Saling membantu(4) Peduli dengan sesama(5) Jujur(6) Dermawan

Sedangkan aqidah diambil dari kata al Aqdu yang artinya al yaqiin atau keyakinan bisa juga di katakan al jazmu yang berarti penetapan. Aqidah di dalam islam yang berarti keyakinan bukannya perbuatan. Seperti adanya keyakinan akan adanya Allah, di utusnya Nabi, Rasul dll.(Farid:33). Aqidah sendiri menurut istilah adalah suatu urusan yang dibenarkan oleh hati dan sudah menancap didalamnya sehingga walaupun ada goncangan yang dahsyat maka tidak akan tergoyahkan. Sedangkan menurut istilah adalah suatu urusan yang dibenarkan oleh hati dan sudah menancap didalamnya sehingga walaupun ada goncangan yang dahsyat maka tidak akan tergoyahkan .

Sedangkan manfaat mempelajari aqidah akhlaq adalah: menjadikan manusia-manusia yang berbudi luhur, bertabiat baik sesuai dengan ajaran islam. Sebenarnya ibadah-ibadah di dalam islam mengajarkan kita untuk berakhlak mulia. Seperti halnya sholat, dengan sholat mengajarkan kita untuk meninggalkan perbuatan-perbuatan yang keji. Di dalam zakat mengajarkan kita selain untuk menyucikan diri juga mengajarkan kita untuk berbagi dengan sesama. Di dalam puasa mengajarkan kita untuk selalu bersyukur dan juga untuk menahan hawa nafsu. Sedangkan di dalam Haji mengajarkan kita untuk memunculkan tenggang rasa dan peduli denga sesama (Anwar Rosihon:25).

Di dalam bukunya yang berjudul pengantar studi akhlaq karya Asmaran mengatakan bahwa secara bahasa (etimologi) akhlaq didalam bahasa arab adalah bentuk jama' dari kata Khulq yang didalam kamus 
al-Munjid yang berarti perangai atau tingkah laku (Asmaran,2009:1) Imam al-Ghazali didalam bukunya Ikhya' Ulum al Din mengatakan bahwa akhlaq adalah: sifat yang tertanam di dalam jiwa yang menimbulkan bermacam-macam perbuatan dengan gampang dan mudah tanpa memerlukan pemikiran dan pertimbangan (Soegarda Poerbakawatdja,1976:9). Jadi bisa disimpulkan bahwa aqidah akhlaq adalah: acuan untuk memilih jalan yang dilakukan oleh seluruh manusia untuk mencapai cita. Jalan itu bisa jalan yang baik maupun buruk tinggal bagaimana manusia memilihnya (Mulyana Dewi,2011:8).

Manusia hidup di dunia ini secara hakiki sudah digariskan untuk saling berhubungan dengan orang lain karena pada dasarnya manusia adalah makhluk sosial. Satu sama lain saling berkaitan hingga terciptalah sebuah keseimbangan yang relativ. Oleh karena itu hendaknya manusia bersikap atau memeliki kepedulian sosial terhadap sesama demi terciptanya keseimbangan dalam kehidupan. Kepedulian sosial adalah sikap atau tindakan seseorang untuk membantu orang lain tanpa adanya niatan lain selain membantu. (Ahmad Muhaimin Azzet, 2011:96) Dan hendaknya setiap manusia memiliki sifat kepedulian sosial. Karena sifat ini adalah cerminan dalam ajaran islam. Karena islam selalu memerintahkan untuk saling berbagi dengan sesama sebagaimana yang terera di dalam surat al Ma'un yang mengisahkan tentang orang-orang yang tidak berkepedulian sosial yang dikecam didalam surat tersebut. Sebagaimana yang tertera di dalam surah al Ma'un yang di dalamnya mengecam kepada orang-orang yang tidak emiliki kepedulian sosisal terhadap orang lain (M.Quroisy Syihab, 2002:644-647).

Selain itu nilai-nilai sosial terdiri atas beberapa sub nilai antara lain adalah: Pengabdian, tolong menolong, kesetiaan dan tolerasni. Sedangkan manfaat memiliki kepedulian sosial antara lain: dapat memupuk menjadi sifat positif, Lebih memperhatikan keadaan sekitar dan terhindar dari sifat egois, Mengurangi beban orang lain, Membuat orang lain bahagia, Tercipta gotong royong, Terciptanya kerukunan dan kekeluargaan, Kesenjangan sosial dapat sedikit ditekan, Terciptanya lingkungan yang menjunjung tinggi persatuan, Menumbuhkan rasa harmonis di lingkungan sekitar.

\section{METODE}

Penelitian ini menggunakan pendekatan deskriptif kualitatif, atau biasa disebut dengan penelitian lapangan dimana peneliti mendeskripsikan segala sesuatu yang berkaitan dengan segala kegiatan yang peneliti teliti kemudian akan di tuangkan dalam kata-kata, informasi berupa naskah, catatan lapangan, dokumntasi, dan lainnya. Bogdan dan Taylor mengatakan bahwa pendekatan kualitatif adalah langkah penelitian yang menghasilkan data deskriptif yaitu berupa data tertulis, kata-kata, atau tingkah laku yang bisa dilihat oleh mata kita (Lexy J. Moeloeng, 2009:4). Jenis penelitian yang dipakai peneliti adalah jenis diskriptif kualitatif yang mempelajari masalah-masalah yang ada serta tata cara kerja yang berlaku. Di dalam penelitian kualitatif peneliti merupakan instrumen yang aktif dalam mendapatkan dan mengumpulkan data. Oleh karena itu peneliti dituntut untuk responsive, dapat segera menyesuaikan diri dengan lingkungan yang baru, berpengetahuan luas, bisa membaca peluang, dapat memproses data dengan cepat dan dapat menekankan keutuhan.

Penelitian ini objeknya adalah kelas X MA Al Quran La Raiba Hanifida. Letak sekolah ini berada di Bandung Kencur, Diwek Jombang Jawa Timur. Sekolah ini merupakan milik yayasan Pesantren Supercamp La Raiba Hanifida. Menurut Suharsimi Arikunto di dalam bukunya yang berjudul prsedur suatu penelitian pendekatan praktek mengatakan bahwa data adalah subjek dimana data itu dapat diperoleh (Suharsimi Arikunto, 2002:107). Di penelitian ini yang disajikan objek data primer adalah adalah siswi kelas X MA Al Quran La Raiba Hanifida, Mrs Nur, Mrs. Aini, Mr. Adib, Ms. Fela, MS. Aghnia, Rahim, Lala dan Rika. Sedangkan sumber data sekundernya peneliti mendapatkan data melalui dokumen, artikel, majalah, arsip dll. Dalam tekhnik analisis data peneliti menggunakan jenis data deskriptif yaitu berupa kata-kata dan tindakan dari orang lain (Lexy J Moeloeng, 2014:248) sedangkan Bogdan mengatakan bahwa analisis data adalah proses menyusun data secara sistematis setelah data diperoleh dari wawancara, observasi dan dokumentasi. Data-data tersebut diolah menjadi data yang mudah difahami dan dimengerti oleh orang lain sehingga jika khalayak umum ingin mempelajari dapat dipelajari secara mudah dan tidak kesulitan. Dan secara umum proses analisi data meliputi : (1) Reduksi data (2) penyajian data (3)verivikasi data

Dalam penelitian ini ada tiga macam tekhnik pengumpulan data diantaranya adalah: observasi, wawancara dan dokumentasi. Setelah data yang diperlukan terkumpul peneliti selanjutnya mengadakan penyaringan terhadap semua data-data yang telah diperoleh. Uji keabsahan data dalam penelitian kualitatif ada tiga. Di antaranya : (1) Perpanjangan keikut sertaan. Di lakukan dengan memerpanjang waktu penelitian. Di harapkan dengan diperpanjangnya waktu penelitian ini penelti semakin mendapatkan kepercayaan yang lebih dari pihak yang di teliti (2) Triangulasi. Triangulasi adalah teknik pemerikasaan keabsahan data yang bisa diambil dari luar. (3) Member Chek. Data yang diperoleh dikonfirmasi baik kepada individu yang bersangkutan atau kelompok diskusi untuk menentukan mana yang disepakati dan tidak (4) Referensi. adanya referensi yang mendukung seperti hasil wawancara, foto dan rekaman yang sudah di laksanakan. 


\section{HASIL DAN PEMBAHASAN}

Nilai-nilai aqidah akhlaq kelas X MA al Qur'an La Raiba Hanifida. Nilai-nilai atau sikap siswi kelas X MA al Qur'an La Raiba Hanifida antara yang satu dengan yang lain tidak sama. Dengan memiliki latar belakang keluarga, sekolah dan lingkungan yang berbeda akan mencetak pribadi siswi yang bermacammacam pula. Contoh dari peristiwa tersebut seperti halnya ketika teman yang lain butuh bantuan ada yang langsung dengan sigap segera membantu tanpa diminta dan ada juga yang dipanggil dulu baru mebantu.

Contoh yang ke dua seperti ketika di pondok atau sekolah mengadakan suatu kegitan atau acara atau program maka ada beberapa anak yang langsung dengan sigap untuk mebantu dan ada juga yang menunggu untuk di panggil. Dengan diadakannya pembelajaran aqidah akhlaq di sekolah mampu sebetulnya mampu untuk meningkatan kepedulian sosial siswi. Akan tetapi akan lebih aksimal jika diimbangi dan didukung dengan kegiatan dan program-program pendukung. Dengan begitu siswi bisa mengetahui nilai-nilai aqidah akhlaq secara teori namun juga mengetahui dan bisa langsung mengamalkan dalam kehidupan sehari-hari.

Dengan diadakannya pembelajaran aqidah akhlaq di kelas akan bisa diimplementasikan dalam kehidupan sehari-hari dan akan menumbuhkan kepedulian sosial. Di harapkan dengan kegiatan tersebut akan mempengaruhi dan meningktakan kepribadian anak bisa : (1) Menyebarkan Ilmu (2) Gotong Royong (3) Saling Membantu (4) Peduli Dengan Sesama (5) Jujur (6) Dermawan. Oleh karena itu pengasuh, kepala sekolah, guru dan pengurus akan terus membuat program dan kegiatan yang melibatkan seluruh siswi sehingga akan menunjang agar siswi dapat dengan maksimal mengimplementasikan pembelajran aqidah akhlaq terhadap kehidupan sehari-hari.

Implementasi nilai-nilai aqidah akhlaq dalam meningkatkan kepedulian sosial kelas X MA al Qur'an La Raiba Hanifida. Implementasi nilai-nilai aqidah akhlaq dalam meningkatkan kepedualian sosial di kelas X MA al Qur'an La Raiba Hanifida diimplementasikan dalam lima kegiatan. Diantaranya adalah: (1) Mengajar ibu-ibu asma Desa Bandung dan Desa Kedawong. (2) Mengajar kilatan dan mengajar TPQ (3) Training (4) Terlibat dalam segala acara (5) Dansos ( Dana Sosial) (6) Baksos (Bakti Sosial).

Kegiatan pertama adalah mengajar ibu-ibu ibu-ibu asma Desa Bandung dan Desa Kedawong. Ibuibu ini sudah berumur sekitar 45 tahun hingga 80 tahun. Di karenakan mempunyai kesibukan kegiatan ini hanya dilakukan dalam satu pertemuan selama satu jam saja. kegiatan ini dilakukan dua kali dalam seminggu bertepatan di hari rabu dan hari minggu. Hari rabu untuk ibu asma Bandung dan hari Kamis untuk ibu asma Kedawong. Walaupun belajar ibu-ibu ini hanya satu jam Alhamdulillah ibu-ibu ini sudah hafal asmaul husna versi 4 bahasa (Indonesia, Jepang, Thailand, Inggris) dan beberapa surat pilihan dan ibu-ibu ini juga sering diundang untuk tampil dalam acara-acara besar dan juga pernah diundang oleh pemerintahan kabupaten Jombang.

Kegiatan ini murni di lakukan oleh siswi. Pengasuh, guru dan pengurus hanya sebagai supervisor. Team devisi logis matematis membagi jadwal dalam setiap pertemuan terdiri dar 2-3 siswi. Siswi ini nanti yang akan mengajar dan diakhir sesi para pengajar akan meminta laporan hasil pembelajar sehingga jaminan kualitas akan terjaga. Kegiatan yang ke dua adalah mengajar kilatan dan TPQ. Kegiatan ini juga murni dilaksanakana dan dikelola oleh siswi. Pengasuh, guru dan pengurus hanya sebagai supervisor. Di kegiatan ini siswi akan mengajar santri kilatan. Santri kilatan sendiri adalah santri yang mondok hanya sebentar dan biasanya dilaksanakan ketika ada liburan sekolah yang panjang. Akan tetapi ada juga yang yang diluar liburan ada yang mengambil kegiatan ini.

Kegiatan ini hampir sama dilakukan ketika mengajar ibu-ibu asma. Perbedaannya terletak didurasi belajar. Ibu asma hanya satu jam dalam satu minggu akan tetapi untuk santri kilatan ini setiap kali pembelajaran durasi waktunya hingga 2 jam dalam 5 kal pertemuan. Petuga devisi logis matematis juga akan membagi jadwal utnuk yang bertugas di hari itu. Melalui kegiatan ini akan menumbuhkan jiwa kepedulian sosial mereka. Selain itu juga akan mengurangi sifat egois mereka karena mereka berbagi dengan yang lain.

Kegiatan selanjutnya adalah mengajar TPQ. TPQ yang di ajar adalah TPQ yang ada disekitar pesantren berumlah dua TPQ. Kegiatan ini dilakukan ketika pada bulan ramadhan dan kegiatan ini murni dilaksanakan dan dikelola oleh siswi. Pengasuh, guru dan pengurus hanya sebagai supervisor. Team devisi training juga akan membagi jadwal yang akan bertugas dalam kegiatan ini. Kegiatan ke tiga adalah training. Kegiatan ini hampir sama dengan kegiatan-kegiatan di atas. Yang membedakan kegiatan ini adalah jangkauan peserta dan tempatnya. Jika mengajar ibu asma dan kilatan hanya berada di pondok dan dalam kelompok kecil jika taining masa pesertanya dalam jumlah besar dan keluar dari pondok. Tidak hanya di dalam negri akan tetapi sampai ke luar negri. Di dalam kegiatan ini tidak semua siswi yang terlibat. Bukan berarti hanya sebagian siswi yang di ajak akan tetapi siswi yang dianggap sudah mampu dan bisa memenuhi standart. Selain itu kegiatan ini juga sebagai ajang untuk memberikan penghargaan untuk siswi-siswi yang memiliki kepedulian yang bagus dan juga untuk merangsang siswi yang lain agar memiliki jiwa kepdulian sosial yag lebih tinggi. 
Di dalam kegiatan ini siswi akan diseleksi oleh devisi training dan akan dirundingkan dengan pengasuh, guru dan pengurus yang lain. Untuk jadwal training pertama siswa akan diberikan jatah di tempat yang terdekat. Jika di tempat tersebut bagus maka akan di lanjutkan dan akan diajak ke tempat lain yang lebih jauh dalam skala local, nasional bahkan internasional.

Kegitan yang ke empat adalah terlibat dalam segala acara. Kegiatan ini melibatkan seluruh siswi dalam melaksanakan kegiatannya. Seperti halnya ketika ada acara akhirussanah, ulang tahun asmaul husna dan al Qur'an, isra'mi'raj, peringatan hari guru dll. Di dalam kegiatan ini siswi berperan aktif dalam menjalankan acaranya. Pengurus pondok dan osis saling berkoordinasi dengan baik dengan melibatkan seluruh siswi mulai dari membungkusi snack, acara, kebersihan dll.

Kegiatan yang ke lima adalah DANSOS. Di dalam dansos ini siswi setiap siswi akan mnyumbangkan sebagian dari uang saku mereka untuk disumbangkan dan hasil dari perkumpulan akan dipergunakan untuk membantu korban bencana alam, membantu teman yang sakit, menjenguk dan memberihadiah kepada guru yang melahirkan, memberi hadiah kepada guru yang menikah, dan memberikan bantuan kepada keluarga santri atau guru yang meninggal.

Kegiatan ini dilakukan dengan cara pengurus osis dan pondok saling bekerjasama untuk mengumpulkan dana tersebut dengan cara mengedarkan kotak amal ke masing-masing kelas sesuai dengan kemampuan mereka. Sebelum mereka mengedarkan kotak amalnya mereka memberikan pengertian kepada siswi akan dipergunaan untuk apa uang tersebut dikumpulkan. Setelah diberikan pengertian dan wawasan mereka mulai mengedarkan kotak tersebut dan hasil dari pengumpulan dana tersebut akan dibelikan suatu barang contohnya kompor, kulkas, tv, kipas angin, box bayi atau uang tunai sesuai kepada siapa mereka akan menyalurkan bantuan tersebut.

Kegiatan ke enam adalah baksos atau biasa disebut dengan bakti sosial. Di dalam kegiatan ini siswi akan diminta untuk mengumpulkan dana dan hasil dana tersebut akan dibelanjakan barang-barang rumah tangga contohnya sepetri ember, gula, minyak, mie, dan kecap dijadikan satu kemudian nantinya akan di bagikan kepada orang kurang mampu. Dengan kegiatan-kegiatan di atas diharapkan seluruh siswi akan menjadi pribadi yang lebih baik dan agar mereka bisa mengimplementasikan ilmu yang ddapat di klas agar tersaluran terhadap kehidupan nyata.

Untuk menunjang atau mendukung kegiatan-kegiatan tersebut supaya berjalan lancar dan hasilnya bisa sesuai yang diharapkan sekolah juga menggunakan penilaian multiple intelegencis. Dengan penilaian ini tidak hanya aspek logis matematisnya saja yang mendapatkan nilai akan tetapi guru akan menilai dari segala aspek. Di dalam penilaian ini guru dan sekolah menggunakan Sembilan penilaian. Di antaranya adalah menggunakan penilaian: (1) kecerdasan intrapersonal (2) kecerdasan interpersonal (3) kecerdasan visual (4) kecerdasan kinestetik (5) kecerdasan musical (6) kecerdasan logis matematis (7) kecerdasan spiritual (8) kecerdasan linguistic (9) kecerdasan natural

Dengan kecerdasan di atas siswi akan di tuntut untuk bisa mengoptimalkan seluruh kecerdasan mereka. Untuk meningkatkan kepedulian sosial siswi maka itu akan meningkatkan kecerdasan intrpersonal siswi. Berawal dari paksaan maka ketika kegiatan it uterus dilakukan maka akan terbiasa dan jika dilakukan terus menerus maka aka menjadi suatu kebiasaan dan jika siswi tidak melakukannya maka akan menjadi gelisah. Berkaitan dengan kegiatan tersebut respon siswi bermacam-macam. Ada yang dengan senang hati mreka menawarkan diri untuk membantu dan ada juga yang harus diberi pegerian sebelum mereka menjalankan tugas.

Proges dari perkembangan siswi ini termasuk bagus. Karena mereka masih kelas X mereka statusnya masih anak baru dan mereka sebelumnya dari sekolah dan lingkugan yang berbeda. Degan melihat progres saat ini sudah bagus aan tetapi pengasuh, guru, dan pengusrus akan mengoptimalkan agar siswi tersebut menjadi siswi yang mempunyai kepribadian sosial yang baik, multitalenta, dan bisa mengimplementasikan semua hasil belajar Selama di kelas bisa di tuangkan dalam kehidupan sehari-hari.

\section{KESIMPULAN}

Ada 6 kegiatan yang menjadi inti dalam penanaman nilai kepedulian sosial. Hal ini diperkuat dengan penilaian ini guru dan sekolah menggunakan Sembilan penilaian. Di antaranya adalah menggunakan penilaian: (1) kecerdasan intrapersonal (2) kecerdasan interpersonal (3) kecerdasan visual (4) kecerdasan kinestetik (5) kecerdasan musical (6) kecerdasan logis matematis (7) kecerdasan spiritual (8) kecerdasan linguistic (9) kecerdasan natural. Sehingga hasilnya bagus dalam menerapkan dan menanamkan nilai kepedulian sosial kepada siswa. 


\section{REFERENSI}

Abduloh, Al Atsari 2006. Intisari Aqidah Ahlussunnah bal Jamaah. Jakarta : Pustaka Imam as-Syafi'i

Azzet, Ahmad Muhaimin 2011. Urgensi Pendidikan Karakter di Indonesia: Revitalitas Pendidikan Karakter Terhadap Kebiasaan Belajar dan Kemajuan Bangsa. Yogyakarta: Dr-Ruzz Media

Gerungan, 2004. Psikologi Sosial. Bandung: PT. Refika Aditama

Kusuma, Yuliandi dan Ardy Artanto. 2011. Internet Untuk Anak Tercinta: Mengawasi Anak Dalam Berselancar di Internet Dengan Parental Control. Jakarta: Grasindo.

Majid, Abdul dan Dian Andyani, 2008. Perencanaan Pembelajaran Mengembangkan Standar Kompetensi Guru. Bandung: PT Remaja Posdakarya

Moloeng, Lexy J., Metode Penelitian Kwalitatif, Kwantitatif, Bandung: Remaja Rosidakarya, 2016.

Rosihon, Anwar 2008. Akidah Akhlak. Bandung: Pustaka Setia

Saifulloh, Ali 1982. Pendidikan dan Pengajaran. Surabaya: Usaha Surabaya

Suharsimi Arikunto, 2010. Prosedur Penelitian Suatu Pendekatan Praktek. Jakarta: Rineka Cipta.

Syihab, .M.Quroisy 2002. Tafsir al-Msibah; Pesan, Kesan dan Keserasian al-Qur'an. Jakarta: Lentera Hati. Zuhraini, 1995. Sejarah Pendidikan Islam. Banda Aceh: Direk. Jend. Pemb. Kelembagaan Agama. 